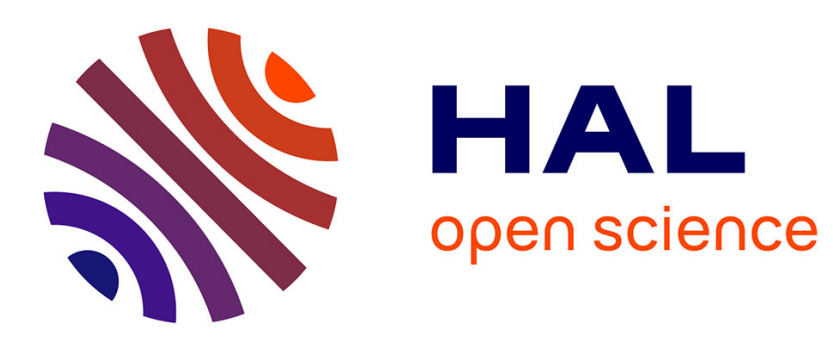

\title{
Monitoring and early detection of internal erosion: Distributed sensing and processing
}

\author{
A. A. Khan, Valeriu Vrabie, Y. L. Beck, Jerome I. Mars, Guy d'Urso
}

\section{To cite this version:}

A. A. Khan, Valeriu Vrabie, Y. L. Beck, Jerome I. Mars, Guy d'Urso. Monitoring and early detection of internal erosion: Distributed sensing and processing. Structural Health Monitoring, 2014, 13 (5), pp.1-15. 10.1177/1475921714532994 . hal-01001765

\section{HAL Id: hal-01001765 \\ https://hal.science/hal-01001765}

Submitted on 4 Jun 2014

HAL is a multi-disciplinary open access archive for the deposit and dissemination of scientific research documents, whether they are published or not. The documents may come from teaching and research institutions in France or abroad, or from public or private research centers.
L'archive ouverte pluridisciplinaire HAL, est destinée au dépôt et à la diffusion de documents scientifiques de niveau recherche, publiés ou non, émanant des établissements d'enseignement et de recherche français ou étrangers, des laboratoires publics ou privés. 


\title{
Monitoring and early detection of internal erosion: Distributed sensing and processing
}

\author{
Amir A Khan', Valeriu Vrabie ${ }^{2}$, Yves-Laurent Beck ${ }^{3}$, Jerome I Mars ${ }^{4}$ \\ and Guy D'Urso ${ }^{3}$
}

\begin{abstract}
Early detection of leakages in hydraulic infrastructures is important to ensure their safety and security. Significant flow of water through the dike can be an indicator of internal erosion and results in a thermal anomaly. Temperature measurements are therefore capable of revealing information linked to leakage. Optical fiber-based distributed temperature sensors present an economically viable and reliable solution for recording spatio-temporal temperature data over long distances, with spatial and temperature resolutions of $\mathrm{I} \mathrm{m}$ and $0.05^{\circ} \mathrm{C}$, respectively. The acquired data are influenced by several factors, among them water leakages, heat transfer through the above soil depth, seasonal thermal variations, and the geomechanical environment. Soil properties such as permeability alter the acquired signal locally. This article presents leakage detection methods based on signal processing of the raw temperature data from optical fiber sensors. The first approach based on source separation identifies leakages by separating them from the non-relevant information. The second approach presents a potential alarm system based on the analysis of daily temperature variations. Successful detection results for simulated as well as real experimental setups of Electricité de France are presented.
\end{abstract}

\section{Keywords}

Embankment dams, surveillance, optical fiber sensors, leakage detection, early warning systems

\section{Introduction}

Electricité de France (EDF), like the other owners of hydroelectric power stations, is concerned by the safety of its water abduction structures. Civil engineering infrastructures like dams and dikes are continuously exposed to water flows. Different aging factors like internal erosion, ground movements, or material heterogeneities introduced during construction/repair affect the stability of these structures. Surveillance of these structures therefore becomes essential to take preemptive actions for the safety of the area. Internal erosion, which can be identified by the presence of leakages, is one of the major causes of disorders in hydraulic structures and could lead to their failure. ${ }^{1}$ Consequently, detection of these leakages and monitoring of their evolution are needed indicators of structural health. The measurement of physical soil parameters such as temperature, self-potential, resistivity, and pore pressure indicates the presence of different anomalies. ${ }^{2-8}$ Different systems have been tested on both laboratory and industrial scales using the above parameters. Among them, pore pressure is very sensitive to infiltration and is a very useful indicator of sudden change in water flow. ${ }^{9}$ However, these pore pressure sensors are not distributed sensors and are quite expensive and fragile. The self-potential measurements have also been deployed recently ${ }^{10,11}$ with some interesting results, but the life of the non-polarizable electrodes used for these measurements prevents longterm monitoring. Geoelectric measurements are less sensitive to low-flow velocity leakages than temperature. ${ }^{6}$

\footnotetext{
'School of Electrical Engineering and Computer Science (SEECS), National University of Sciences and Technology, Islamabad, Pakistan ${ }^{2}$ Centre de Recherche en STIC (CReSTIC), University of Reims, Reims, France

${ }^{3}$ Electricité de France (EDF), Grenoble, France

${ }^{4}$ Department Images and Signal, GIPSA-Lab, Grenoble Institute of Technology, Grenoble, France
}

\section{Corresponding author:}

Amir A Khan, School of Electrical Engineering and Computer Science (SEECS), National University of Sciences and Technology (NUST), H-12, Islamabad-44000, Pakistan.

Email: amir.ali@seecs.edu.pk 
In case of a significant flow through a structure, temperature is a natural indicator of leakage owing to the alteration of thermal distribution. Although the idea of leakage detection using thermal measurements is quite old, ${ }^{12}$ they are mostly carried out locally and without automatic repetition. ${ }^{13}$ In brief, the large stretch of structures such as dikes, spreading over several kilometers, limits the application of conventional temperature monitoring techniques. On one hand, these techniques require careful placement of temperature sensors, and on the other hand, they require continuous human intervention. These techniques, therefore, have limited scope in the context of preventive maintenance. Long-range and continuous monitoring requirements necessitate development of innovative monitoring solutions capable of generating automatic alerts with centralized control. These solutions will complement the existing auscultation methods such as visual inspections of the structure. In this regard, this case study will demonstrate a system based on optical fiber temperature sensors and signal-processing techniques for detection of leakages in dikes. The optical fiber sensors used in this case study are based on distributed temperaturesensing (DTS) technology. ${ }^{14}$ The underlying principle is that the optical fiber acts as an intrinsic distributed sensor, offering numerous advantages over the conventional sensors. ${ }^{15,16}$ The possibility of multiplexing a large number of sensors on a single optical fiber and the flexibility of sensor placement are some of the unrivaled advantages of DTS. Moreover, the long-range measurement capability $(>20 \mathrm{~km})$ with typical spatial resolution of $1 \mathrm{~m}$ and temperature resolution of $0.05^{\circ} \mathrm{C}$ gives these sensors a distinct edge. Owing to the use of low-cost telecommunication-grade optical fiber, these sensors present an economically viable solution without compromising the measurement quality. Numerous inherent advantages offered by the optical fibers include immunity to electromagnetic interference and durability (life over 30 years), proven through direct feedback from wide applications in the telecommunication industry.

The optical fibers are buried at a strategic location inside or close to the dike (e.g. downstream toe) in order to intercept a leakage. However, for real on-site installations, the leakage is not the only factor influencing the recorded temperature. Several other environmental factors, such as existing structures (drains), self-response of the ground in which the fiber is buried, seasonal temperature variations, precipitation, and so on, equally influence the acquired data. Leakage identification from recorded temperature signals thus calls for development of suitable processing and detection methodologies.

The detection methodologies can be broadly classified as physico-statistical and signal-processing based.
The physico-statistical methods are based on the approximation of impulse response of heat equation to model the thermal behavior of the dike. ${ }^{17}$ This article focuses on the methods based on advanced signalprocessing techniques exploiting only temperature signals from optical fiber without any a priori on the air and canal water temperatures. Two analysis approaches will be presented, a medium-term (fortnightly) approach based on source separation techniques ${ }^{18}$ and a short-term (daily) alarm approach based on singularity detection. ${ }^{19}$ EDF has been studying the internal erosion phenomenon for a couple of years and has equipped several of its dikes with distributed optical fiber temperature sensors. The application of the developed methodologies will be demonstrated for data simulated through numerical modeling as well as data recorded at different experimental sites of EDF.

After a description of temperature data acquisition system using optical fiber sensors, the synthetic data generation model and an overview of experimental sites are presented. The proposed leakage detection methodologies are then exposed, followed by the results of their application on different scenarios showing their efficiency for leakage detection. This article is concluded with a comprehensive discussion.

\section{Leakage monitoring by optical fiber sensors}

Recent case studies on embankment dams have pointed that $46 \%$ of the failures result from internal erosion. ${ }^{1,20,21}$ Internal erosion corresponds to the movement of soil particles under the influence of significant flow through a dike. Even though physical parameters such as electrical resistivity and dielectric permeability are implicitly affected by internal erosion, ${ }^{4}$ temperature has a more direct link to it in case of leakages, hence the use of thermal methods for monitoring of hydraulic structures. ${ }^{12,21,22}$ These studies have shown the sensitivity and reliability of thermal measurements for identification of significant flows in the embankments, thus making them a natural choice for dike surveillance. Dikes being spread over several kilometers, costeffective methods must be employed. In this regard, the temperature measurements using optical fibers are an adapted limited-cost solution, compatible with quasivisual inspection along the entire dike length.

\section{Principle of optical fiber-distributed temperature sensors}

Figure 1 shows a typical installation of optical fiber at the downstream toe of the canal, being interrogated by a DTS device placed in a specific instrumentation room. 


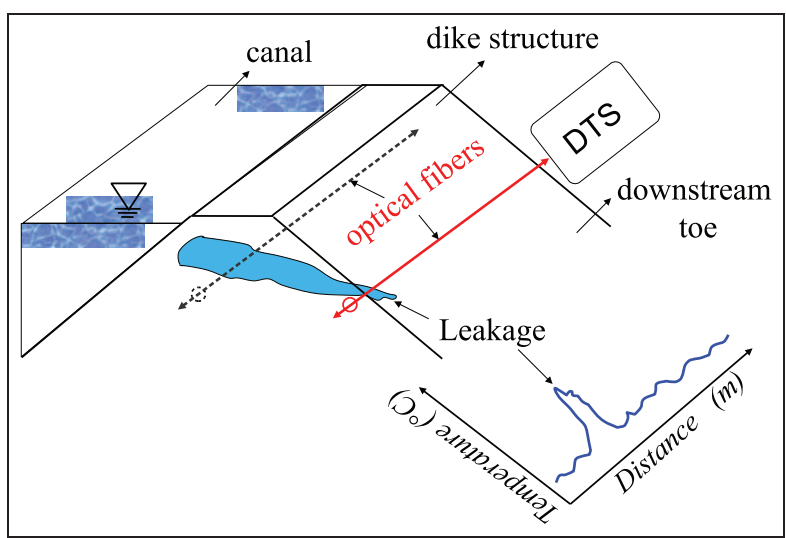

Figure I. Principle of leakage detection by optical fiber thermometry. The circles show two fictitious positions of the optical fiber: the dotted one somewhere in the middle of the dike and the solid one toward the downstream toe. The optical fiber is connected to the distributed temperature-sensing (DTS) equipment placed at the power station. The temperature measured by the fiber shows a gradient at the location where fiber intercepts the leakage.

The optical fiber can be placed at different positions inside the dike. Two fictitious positions of fiber marked by circles are shown in Figure 1, where the dotted circle is somewhere in the middle of the dike and the solid one toward the downstream toe of the dike.

The principle of measurement is the detection of thermal anomaly provoked by preferential flow through the dike structure. The origin of this thermal anomaly is a sudden variation of heat transport. In the absence of anomalies, the heat transfer is uniquely caused by conduction: the heat transfer is attributed to the interaction between air temperature and temperature of water naturally present in the ground, without the presence of any flow. Significant water flow through the dike brings an additional heat component driven by the phenomenon of convection. In brief, profound thermal analysis allows leakage detection by horizontal convection, that is, the transport of heat due to the canal water flowing through the previously segregated or subsequently eroded soil layers. This flow modifies the normal temperature field due to conduction. The optical fiber can therefore intercept the temperature changes. The commercial DTS equipment is based on Raman's scattering using the optical timedomain reflectometry (OTDR). ${ }^{14}$ The major components of the system are the following: a pulsed laser source, a directional coupler, and an optical fiber cable, the intrinsic temperature-sensing element. The measurement principle is very similar to that of a radar. The light photons emitted by the laser source interact with the molecules of the fiber material. Some of the photons are backscattered by thermally induced molecular vibrations, attributed to Raman scattering. The Raman spectrum consists of two backscattered components, at equidistant frequencies around the incident frequency. The intensity ratio between the temperature-dependent anti-Stokes and temperatureindependent Stokes components gives the temperature as a function of return time to the emitting source. Since the speed of light inside the fiber is known, noting the travel time, the temperature can be formulated as a function of distance along the entire fiber length.

There exists a trade-off between different parameters of DTS device such as spatial and temperature resolutions, speed of measurement, range, and signal-to-noise ratio. ${ }^{23}$ As an example, the temperature resolution decreases with increasing spatial measurement range for a fixed measurement time. Likewise, the signal-tonoise ratio can be improved by allowing DTS device more time for signal acquisition at the cost of reduced measurement speed. The initial installation also requires proper calibration with respect to some reference temperature. For this study, the temperature data were recorded using a Raman DTS device, which offers a temperature resolution of $0.05^{\circ} \mathrm{C}$, a spatial resolution of $1 \mathrm{~m}$, and a range of $5 \mathrm{~km}$.

A water leakage across the dike generates a thermal anomaly recordable by the optical fiber. Several measurements over time allow following the temporal evolution of this anomaly. The acquired raw temperature data can thus be formulated as a function of distance and time. It is, however, difficult to identify the leakage signatures on the raw temperature data due to the influence of several environmental factors. Consequently, subsequent data processing is required in order to isolate information specific to the leakages.

\section{Data and experimental site}

Two thermometric data sets were used for analysis in this article. The first set is composed of simulated temperature data in a completely controlled environment, whereas the second one is the real temperature data acquired at an experimental installation of EDF in the south of France.

\section{Synthetic data}

In the context of numerical modeling of physical interactions inside dikes, Guidoux ${ }^{24}$ modeled the temperature field at different positions inside a dike subjected to a hydraulic head. This modeling involves numerical solution of heat transfer equation using finite element method. ${ }^{25}$ The modeling aspect does not fall into the scope of this article, and only the final simulated temperature data will be presented here. The main contribution of this article being the data analysis methods, 


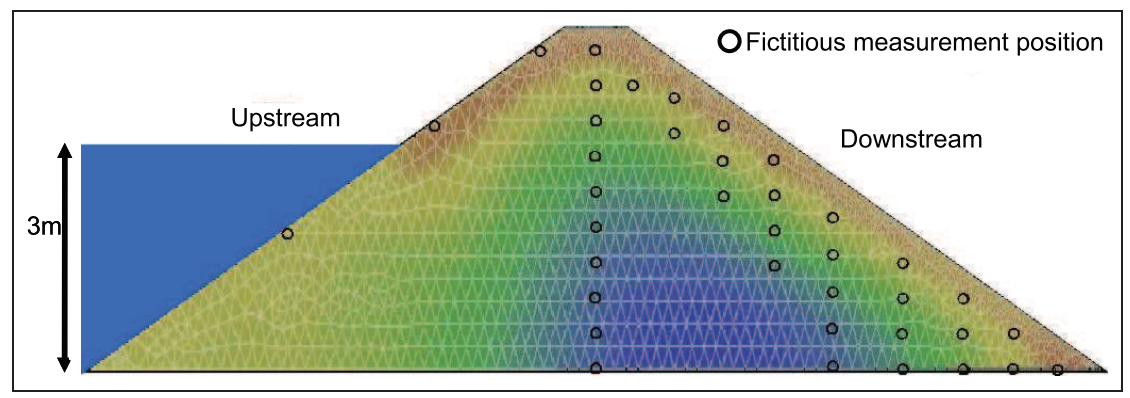

Figure 2. Temperature simulated along the cross section of a dike at different fictitious fiber positions at a given time. The hydraulic charge imposed at the upstream is $3 \mathrm{~m}$.

Table I. Flow rate and velocity as function of soil nature and permeabilities.

\begin{tabular}{|c|c|c|c|c|}
\hline \multicolumn{2}{|c|}{ Soil type } & \multirow{2}{*}{$\begin{array}{l}\text { Hydraulic conductivity }(\mathrm{m} / \mathrm{s}) \\
10^{-3} \\
10^{-4} \\
10^{-5} \\
10^{-7}\end{array}$} & \multirow{2}{*}{$\begin{array}{l}\text { Flow rate }(\mathrm{L} / \mathrm{min}) \\
10.8 \\
1.1 \\
0.1 \\
0.001\end{array}$} & \multirow{2}{*}{$\begin{array}{l}\text { Maximum velocity }(\mathrm{m} / \mathrm{s}) \\
1.74 \times 10^{-4} \\
1.74 \times 10^{-5} \\
1.74 \times 10^{-6} \\
1.74 \times 10^{-8}\end{array}$} \\
\hline Alluvia & $\begin{array}{l}\text { gravel } \\
\text { sand } \\
\text { silty-sand } \\
\text { silt }\end{array}$ & & & \\
\hline
\end{tabular}

the results on this simulated data set will be discussed later.

The thermal field simulated for a two-dimensional (2D) trapezoidal dike cross section is shown in Figure 2 for a depth-dependent hydraulic head between 0 and $3 \mathrm{~m}$ imposed at upstream. Moreover, 38 different fictitious optical fiber positions were simulated inside the dike at different depths and distances from the upstream toe (Figure 2). These fictitious positions were modeled to study the influence of fiber placement transversally across the dike: stretching from upstream to the downstream toe of the canal. We thus have temperature over time but need to simulate temperatures over a certain dike length (longitudinally). The sampling interval was fixed at $2 \mathrm{~h}$ in order to have 12 acquisitions per day, and temperature data were simulated for a period of 2 years.

Depending on their respective hydraulic conductivities, different types of soil, subjected to the same hydraulic head, will have different temperature distributions. Table 1 enlists the characteristics of the alluvium (material used in most dikes in France): the maximum flow rate is obtained for gravel having thermal conductivity of $10^{-3} \mathrm{~m} / \mathrm{s}$ and the minimum for loam (silt) with a thermal conductivity of $10^{-7} \mathrm{~m} / \mathrm{s}$. The modeled temperature will be either close to that of air or that of water. It was observed that hydraulic conductivities of $10^{-3}$ and $10^{-7} \mathrm{~m} / \mathrm{s}$ result in temperatures similar to that of water and air, respectively. The hydraulic conductivity of $10^{-4} \mathrm{~m} / \mathrm{s}$ is closer to that of water than to air albeit with some phase shift. The hydraulic conductivity of $10^{-5} \mathrm{~m} / \mathrm{s}$ presents a complex case, where the modeled temperature is in phase with that of air but with a reduced amplitude. This later observation means that a slight influence of water may still be present for this conductivity. The maximum velocity is related to the hydraulic conductivity and determines the Peclet number. This number, in turn, determines the proximity of the temperature captured by fiber either to that of air or of water. Higher the velocity of leakage, higher will be the Peclet number and closer would be the captured temperature to that of water. The corresponding Peclet numbers for gravel and sand were on the higher side of the order of 4 , whereas they were of the order of 0.4 for silt and around 2 for silty sand. A 1-km-long dike is simulated using two homogeneous soil layers offering smallest flow rates with the hydraulic conductivities of $10^{-7}$ and $10^{-5} \mathrm{~m} / \mathrm{s}$, respectively. These layers allow simulating the temperature along the optical fiber length without leakages. A drain and two leakages were added to this base model. The drain, an anomaly existing at all instants of time, possibly with slow variations over time, is simulated using the modeled temperature for permeability of $10^{-4} \mathrm{~m} / \mathrm{s}$ at a fictitious measurement point under the water level. The drain was introduced at a distance of $0.32 \mathrm{~km}$ from the emitting source. Two leakages labeled $F S 1$ and $F S 2$ were hypothesized at distances of 0.087 and $0.747 \mathrm{~km}$ from the emitting source, using a saturated hydraulic conductivity of $10^{-3} \mathrm{~m} / \mathrm{s}$. The effect of local fracture at a sufficient distance from upstream is assumed to be spread over a fiber length of $2 \mathrm{~m}$. This hypothesis is also related to the fact that the optical fiber has a spatial resolution of $1 \mathrm{~m}$ and cannot resolve multiple fractures within $1 \mathrm{~m}$. The duration of 


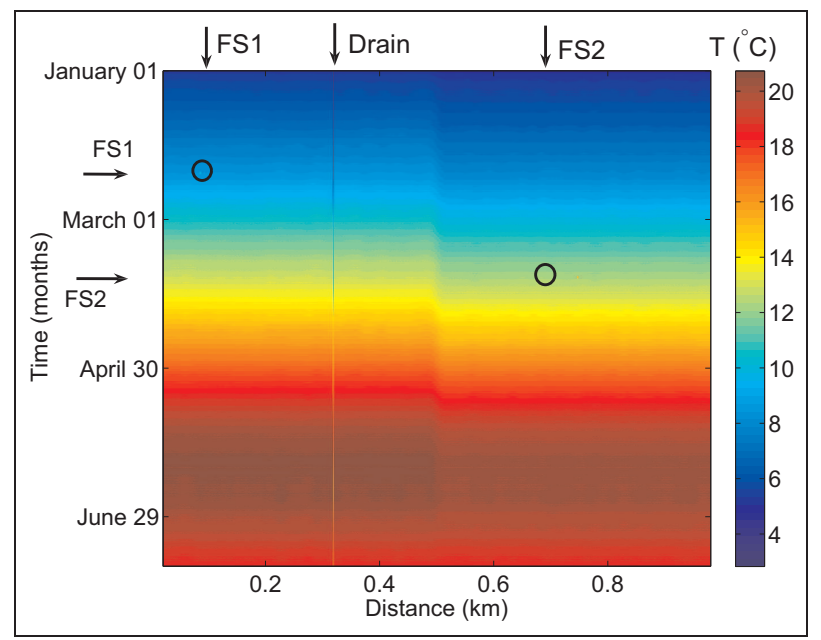

Figure 3. Simulated raw temperature data with two homogeneous areas $(0-0.5 \mathrm{~km}$ and $0.5-1 \mathrm{~km})$ containing a drain $(0.32 \mathrm{~km})$ and two leakages of I-day duration, labeled FSI (87 and $88 \mathrm{~m}$ on February II) and FS2 (747 and $748 \mathrm{~m}$ on March 23) and localized under black circles. Colors represent the simulated temperatures.

the leakages is chosen to be 1 day (February 11 for $F S 1$ and March 23 for FS2) for testing the daily analysis system. Leakages spanning over several days were also tested and will be discussed in "Results and discussion" section. Finally, to take into account the measurement noise, spatially and temporally white Gaussian noise is added to the data with a standard deviation of 0.02 . The noise parameters were estimated through laboratory tests carried out with the DTS device. The resultant synthetic data set is shown in Figure 3 over a period of 6 months. The two coordinates represent time and distance, whereas different colors represent the scale of simulated temperature with seasonal variations from winter to summer. The first of the two homogeneous layers extends up to $0.5 \mathrm{~km}$ from emitting source, whereas the second extends from 0.5 to $1 \mathrm{~km}$. The abrupt gradient appearing vertically at $0.5 \mathrm{~km}$ represents the change of hydraulic conductivity. The drain manifests itself for the whole span of the simulated data with slowly varying temperature over time. It is distinguishable from the homogeneous layers because of its higher hydraulic conductivity $\left(10^{-4} \mathrm{~m} / \mathrm{s}\right)$. The two leakages with the highest conductivities are marked with circles and offer a significant temperature gradient with respect to their surroundings. Their isolation from the background would be depicted in the "Results and discussion."

\section{Real experimental site}

In fulfillment of dike surveillance using optical fiber temperature sensors, EDF has equipped several sites

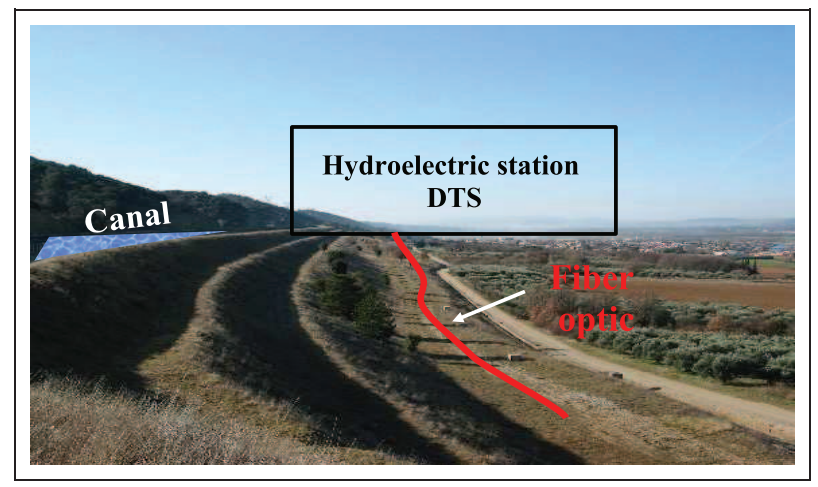

Figure 4. Real dike of EDF bounding the feed canal of the hydroelectric station: illustration of location of optical fiber at the toe of the dike.

EDF: Electricité de France; DTS: distributed temperature sensing.

along its hydraulic power stations. In order to validate the temperature data analysis methods, an EDF installation located in south of France is considered for this article.

Site description. An optical fiber-based thermometric system is installed at the dike enclosing the inlet canal that feeds the hydroelectric power house (see Figure 4) with an aim to extract information pertaining to leakages (location, flow rate, and so on). The dike is constituted of alluvium with a rubble mixture of rock type (pudding stone) and silt loam, whereas the water confinement of the dike is ensured by concrete slabs. The real leakages could, for example, appear due to disruption of joints or opening of small cracks. The optical fibers were installed over about $2 \mathrm{~km}$ along the dike, up to the power station, this choice made owing to previous studies and suspicion of some leakages in this zone. ${ }^{2}$ The distance over which the optical fibers are installed depends on the history of visual inspections for already built embankments or on the coarse location of potentially suspect zones. The new installations can be equipped with optical fibers over ranges extending to about $30 \mathrm{~km}$ with short-segment terminations over this length. These individual segments can then be monitored simultaneously or independently. In either case, the sensing fiber cable should be placed behind the sealing system of the dam in order to intercept the changes in temperature due to the presence of a water flow through the dam (e.g. directly underneath the upstream sealing face, in the drainage layer behind the low permeable core or at the downstream toe). At the installation described in this case study, a cable containing four optical fibers was installed at the downstream toe of the canal at $1 \mathrm{~m}$ depth (Figure 5). The fiber location was chosen to best capture the potential 
leakages in the dike. The optical fiber is buried at about $30 \mathrm{~m}$ from the canal in the dike toe for the first kilometer and then passes on the berm for its remaining length. The schematic representation of the layout is shown in Figure 6. The configuration presents two distinct elevation levels (Zone 1, from 0.1 to $1.25 \mathrm{~km}$ and Zone 2, from 1.25 to $2.2 \mathrm{~km}$ ), which exhibit two different thermal behaviors partly due to different soil properties and partly due to different influences of solar radiations (inclination, absorption). In its path, the optical fiber cable circumvents two drains which serve to drain out the water toward the drainage canal in case of infiltration in the edifice. The drains, hereafter

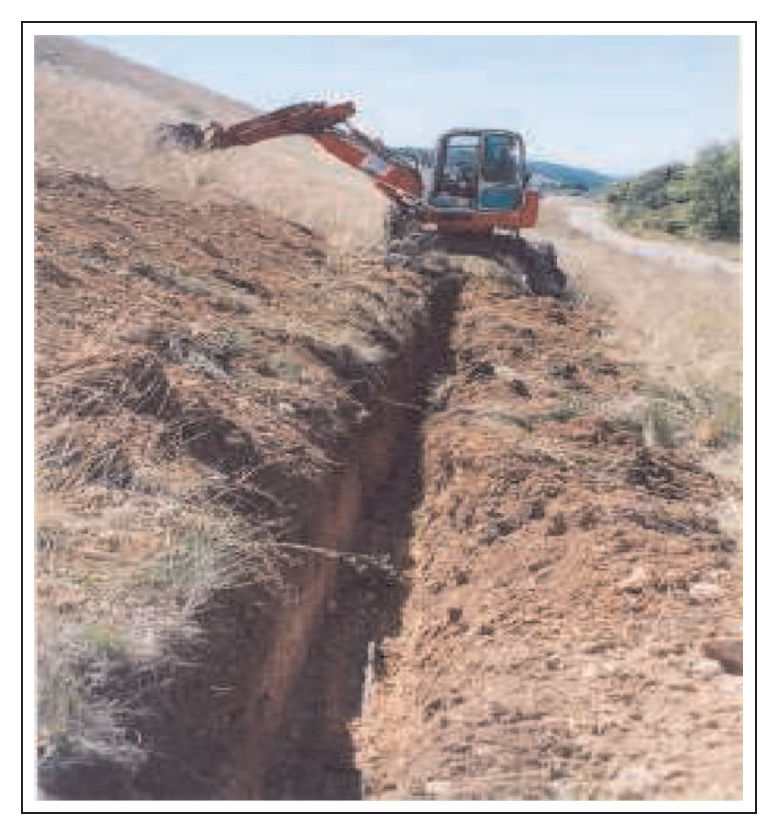

Figure 5. Digging up of the trench for optical fiber installation along the dike. labeled $D 1$ and $D 2$, provoke a peculiar thermal response and constitute a distinguishable type of anomaly. In addition to Zones 1 and 2, the soil is not homogeneous along the entire fiber length. The fiber terminates into the DTS device placed in an instrumentation room in the hydraulic station.

Artificial test leakages. In order to validate the acquisition system and leakage detection analysis methods, tests of artificial percolation type leakages were carried out. These leakages were controlled in terms of their flow rate, location, and timing. In general, the procedure consisted of bringing the canal water to the zone where fiber is buried with the help of a pipe. A control valve allowed regulation of downstream flow rate to simulate different leakages. In particular, three leakages, $L 1, L 2$, and $L 3$, were simulated between 10 and 12 May 2005 (Table 2). It should be mentioned that water temperature at pipe exit is not necessarily the same as that of the canal due to the influence of solar radiation. Moreover, a hot point, denoted by $H P$, consisting of hot water pouring on the fiber, was also simulated at a distance of $0.674 \mathrm{~km}$. This hot point serves to test the proper installation of the optical fiber and the DTS monitoring equipment. Figure 7 shows the raw temperature data recorded at the experimental site between 12 April 2005 and 13 October 2005 as a function of time and distance.

It is not necessary for the optical fiber to be directly in contact with water leakage from system installation perspective. The direct contact will obviously ensure easy detection, but it is not a limiting factor. It has been shown that the measured temperature provides information on the surrounding of the optical fiber in a radius of about $1 \mathrm{~m}$, the exact value depending on local geological parameters. ${ }^{26}$ The identification of the leakages on the raw temperature data is not

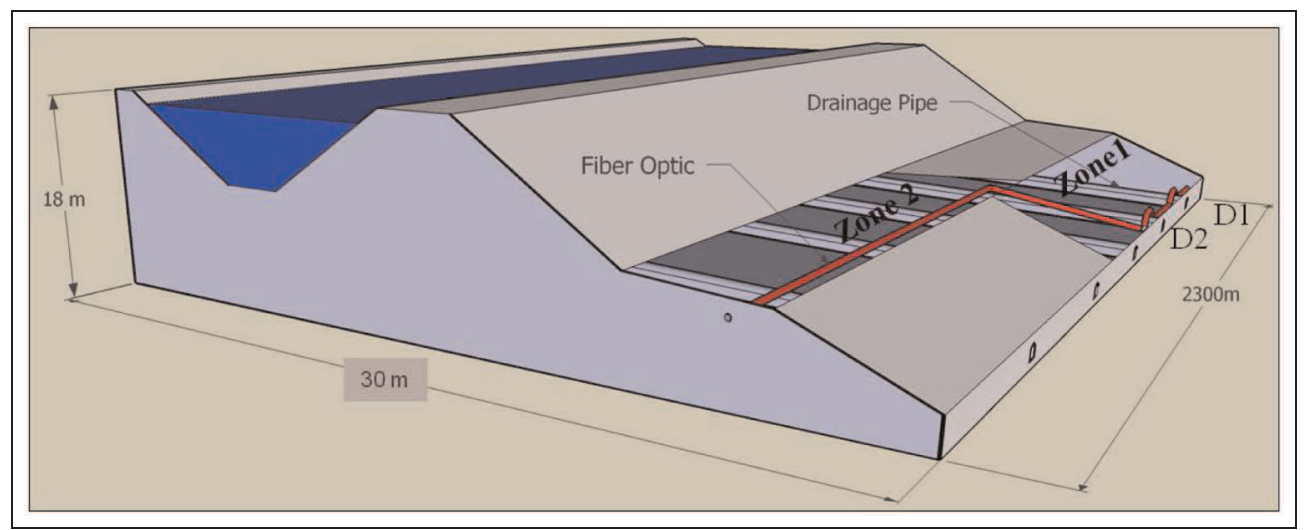

Figure 6. Optical fiber layout at the real site showing two different elevation levels: Zones I and 2. The fiber also circumvents two drains (DI and D2). 
Table 2. Characteristics of structures and artificial leakages at the experimental site.

\begin{tabular}{|c|c|c|c|c|c|c|}
\hline & \multicolumn{2}{|c|}{ Drains } & \multicolumn{3}{|l|}{ Leakages } & \multirow{2}{*}{$\begin{array}{l}\text { Hot point } \\
\text { HP }\end{array}$} \\
\hline & $\overline{\mathrm{DI}}$ & D2 & $\overline{\mathrm{LI}}$ & L2 & L3 & \\
\hline Distance $(\mathrm{km})$ & 0.561 & 0.858 & 1.566 & 1.551 & 1.573 & 0.674 \\
\hline Date (May) & - & - & 10 (afternoon) & 12 (afternoon) & 12 (evening) & 10 (morning) \\
\hline Flow rate $(\mathrm{L} / \mathrm{min})$ & - & - & 5 & 1 & I & - \\
\hline
\end{tabular}

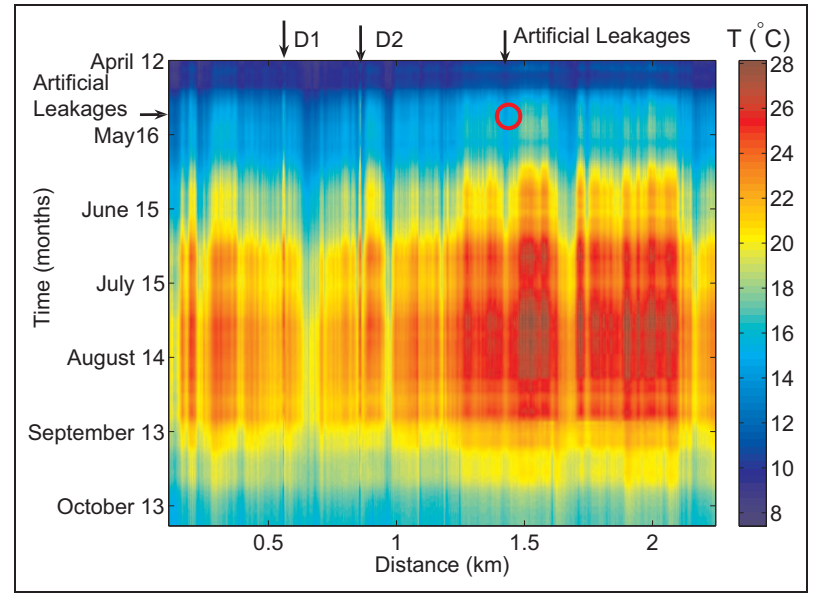

Figure 7. Raw temperature data acquired at experimental test site over a length of $2 \mathrm{~km}$ from 12 April to 13 October 2005 containing the drains (DI at $0.56 \mathrm{I} \mathrm{km}$ and $D 2$ at $0.858 \mathrm{~km})$ and artificial leakages $(L I, L 2$, and $L 3)$ localized in the circle.

straightforward, thus requiring data analysis methods. The signal-processing methods for leakage detection are the subject of next section.

\section{Leakage detection methodologies}

The data recorded by the optical fiber can be written as a 2D signal, $y(t, x)$, function of time $t$ and the distance $x$

$$
\mathbf{Y}=\left\{y(t, x) \mid 1 \leq t \leq N_{t}, 1 \leq x \leq N_{x}\right\}
$$

with $N_{t}$ and $N_{x}$ representing, respectively, the total number of acquisitions (time) and the number of sensors (distance). The underlying assumption of thermal measurements is that significant flow of water due to leakages could be identified by measuring the difference of temperature between that of the canal and the soil in which the fiber is buried. However, this difference could easily be caused by other factors such as the existing structures (drains, tunnels, and manholes), seasonal temperature variations, solar radiation, precipitations, soil heterogeneities, and so on. Moreover, the acquired signal is strongly influenced by response of the near surface where fiber is buried, partly hiding the leakagerelated information. Secondary factors such as wind and humidity may also influence the acquired signal. In brief, signal-processing techniques must be applied on the raw temperature data in order to detect the anomalies and among them those due to the leakages. Theoretically, the recorded signal can be modeled as a mixture of above factors. Even though these factors can be a non-linear function of temperature, we consider only the temperature values induced by these factors without trying to quantify the factors which produced these values. A source of temperature (as function of distance along the fiber) is attributed to different factors allowing to express the recorded temperature as a weighted linear mixture of these factors. In addition, considering the physical independence of these factors, the associated temperature sources can be considered independent. The temperature matrix is thus expressed as

$$
\mathbf{Y}=\mathbf{M F}+\mathbf{B}
$$

where $\mathbf{M} \in \Re^{N_{t} \times p}$ represents the mixing matrix (the weights), $\mathbf{F} \in \Re^{p \times N_{x}}$ the independent sources induced by the factors, $\mathbf{B} \in \Re^{N_{t} \times N_{x}}$ the noise, and $p$ the number of sources. Different preprocessing techniques such as data deseasoning and normalization could be employed for attenuating the influence of certain factors. ${ }^{18}$ Likewise, the temporal periods of precipitations must be identified as they could introduce false alarms in the detection algorithms. In this regard, a criterion for identifying such periods, based on higher order statistics (kurtosis), was proposed ${ }^{27}$ but will not be described in this article.

\section{Medium-term analysis: source separation approach}

The optical fiber allows monitoring of temperature along the dike with metric resolution. Thereafter, an approach based on the separation of different thermal contributions (sources) could be adopted. The most commonly used techniques for source separation are singular value decomposition (SVD) ${ }^{28}$ and independent component analysis (ICA). ${ }^{29,30}$ 
The SVD of the data matrix $\mathbf{Y}$ can be expressed as

$$
\begin{aligned}
\mathbf{Y}= & \mathbf{U}_{N} \Sigma_{N} \mathbf{V}_{N}^{T}=\mathbf{Y}_{\text {ground }}+\mathbf{Y}_{\text {useful }}=\sum_{k=1}^{m} \sigma_{k} \mathbf{u}_{k} \mathbf{v}_{k}^{T} \\
& +\sum_{k=m+1}^{N} \sigma_{k} \mathbf{u}_{k} \mathbf{v}_{k}^{T}
\end{aligned}
$$

where $N=\min \left(N_{t}, N_{x}\right), \Sigma_{N} \in \Re^{N \times N}$ is a diagonal matrix containing the singular values $\sigma_{j} \geq 0$, arranged in a descending order, and $\mathbf{U}_{N} \in \Re^{N_{t} \times N}$ and $\mathbf{V}_{N} \in \Re^{N_{x} \times N}$ are orthogonal matrices, containing $N$ left and right singular vectors $\mathbf{u}_{j} \in \Re^{N_{t}}$ and $\mathbf{v}_{j} \in \Re^{N_{x}}$, respectively. The decomposition of raw data matrix into orthogonal matrices allows estimation of desired sources, $\mathbf{v}_{j}$, that are decorrelated and normalized. The decorrelation allows extraction of Gaussian sources but the leakages and the drains are better modeled by non-Gaussian sources. Nevertheless, as given by equation (3), SVD allows decomposition of data into two subspaces, the ground subspace, $\mathbf{Y}_{\text {ground }}$, and the subspace, $\mathbf{Y}_{\text {useful }}$, containing leakages. SVD being a second-order method is not sufficient for separation of leakages within the useful subspace. A more realistic approach, based on the ICA, is applied on the useful subspace. ICA is a blind decomposition technique, requiring no a priori information about the sources, based on the assumption that the sources are mutually independent. The goal of ICA is to estimate the sources and their contributions to the mixture by maximizing a criterion of statistical independence. The algorithmic details do not fit into the scope of this article, and the interested readers can refer to Hyvärinen et al., ${ }^{29}$ Comon and Jutten, ${ }^{30}$ and Cardoso and Souloumiac. ${ }^{31}$ Taking $\mathbf{Y}_{\text {useful }}$ at its input, ICA allows separation of leakage-related subspace, $\mathbf{Y}_{\text {leakage }}$, from the rest of the signal, $\mathbf{Y}_{\text {rest }}$, thus allowing leakage detection as follows

$$
\begin{aligned}
\mathbf{Y}_{\text {useful }} & =\sum_{j=m+1}^{m+q} \tilde{\boldsymbol{\sigma}}_{j} \tilde{\mathbf{u}}_{j} \tilde{\mathbf{v}}_{j}^{T}+\sum_{j=m+q+1}^{m+p} \tilde{\boldsymbol{\sigma}}_{j} \tilde{\mathbf{u}}_{j} \tilde{\mathbf{v}}_{j}^{T}+\mathbf{B} \\
& =\mathbf{Y}_{\text {rest }}+\mathbf{Y}_{\text {leakage }}
\end{aligned}
$$

where $\tilde{\mathbf{v}}_{j}$ represents independent sources obtained from decorrelated ones $\mathbf{v}_{j}$. The algorithm is summarized by the schematic of Figure 8. The important parameters are $m$, the number of singular values for constructing ground subspace; $p$, the number of ICA sources to be estimated and the analysis period (usually $2-3$ weeks). ${ }^{18}$ Different empirical tests were done in order to find the best compromise for these parameters and will be discussed in the "Application of source separation approach" section.

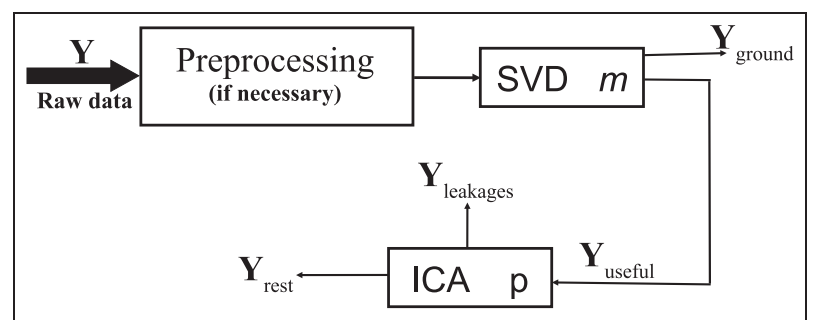

Figure 8. Synoptic of source separation-based leakage detection methodology. The different controlling parameters are " $m$," the number of singular values for constructing ground subspace, and " $p$," the number of ICA sources to be estimated. SVD: singular value decomposition; ICA: independent component analysis.

\section{Short-term analysis: alarm system approach}

The method of leakage detection using source separation approach is useful when we have a large number of acquisitions, as in the case of monitoring. In this section, a daily alarm system is proposed with an aim to identify the anomalies whose behavior change in the course of a day. The method is based on the analysis of daily temperature variations at different distances with an aim to localize the singularities caused by leakages, existing structures, ground singularities, and so on. The different stages of the proposed technique are summarized in Figure 9. The system is based on the fact that distances corresponding to singularities (leakages for instance) present daily temperature variations different from those of non-singular zones. The system therefore processes data for a given day " $k$ " at all the sensing distances. The meteorological conditions are first verified to ensure precipitation free days with precipitation assumed to effect quasi-whole of the fiber. ${ }^{27}$ The next step is to estimate a reference vector representing the 24-h temperature variation for non-singular zones. Different possibilities exist for estimating this reference (e.g. using the air or water temperature) but the proposed approach exploits only the data captured by the optical fiber and thus estimates this reference from the data itself using SVD. ${ }^{19}$ The difference with respect to this reference (in terms of Euclidean distance or others) allows formulating a measure of dissimilarity with the help of $L_{2}$ norm. The resultant dissimilarity measure, $d_{k}(x)$, is a function of distance. However, this measure is noisy due to estimation errors and the instrument noise. For robust singularity detection, this dissimilarity, $d_{k}(x)$, is modeled as a mixture of gamma distribution (for non-singular samples) and uniform distribution (for singular samples). The corresponding distribution parameters are identified using the maximum likelihood approach with the help of histogram 


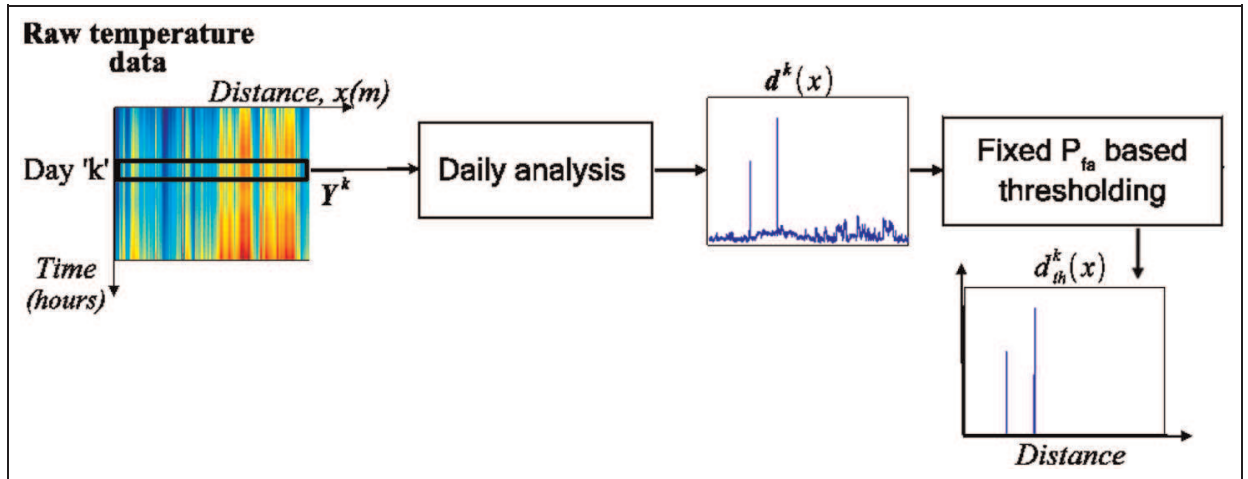

Figure 9. Synoptic of daily dissimilarity-based analysis methodology. $k$ represents the analyzed day. $d^{k}(x)$ represents the dissimilarity measure whereas the detection parameter is represented by $d_{t h}^{k}(x)$.

of $d_{k}(x)$. Instead of having a fixed threshold for each analysis day, a probability of false alarm, $P_{f a}$, is fixed to calculate an optimal threshold for day $k$. The output is the thresholded dissimilarity, $d_{t h}$, a detector of singularities.

\section{Results and discussion}

This section will focus on the results obtained by the application of the proposed methods on simulated and real temperature data.

\section{Application of source separation approach}

The source separation-based scheme of Figure 8 is applied on the raw temperature data. In the first instance, the normalization of the raw temperature is carried out in order to attribute the same importance to all the sensors while simultaneously attenuating the effects of seasonal variations. The simulated temperature data (Figure 3) were chosen as the input of the schematic with parameters $m=1$ and $p=4$, and the analysis was carried out in sliding temporal windows of 20 days. The choice of these parameters is empiric: $m=1$ is used to estimate a source corresponding to the geology using SVD, whereas $p=4$ represents the number of sources to be estimated by ICA, and its choice is data dependent. It was observed that the first source obtained by SVD accounted for about $40 \%$ of the total signal (in terms of singular values, $\sigma$ ). It reveals two different levels corresponding to different materials used for simulating the non-singularity zones and can thus be associated with the ground response. The subsequent analysis with ICA gives the leakage detection subspace, $\mathbf{Y}_{\text {leakages }}$, as presented in Figure 10(a). This spatio-temporal representation of the detection result allows leakage localization in distance and time with a spatial resolution of $1 \mathrm{~m}$ and a temporal resolution of
2 h. The leakages $F S 1$ and $F S 2$, spanning over a day each, are quite well localized as depicted by the zoom in their vicinity. Limiting ourselves to the leakage detection in distance, the detection image can be projected on the distance axis for the analysis period. Figure 10(b) shows the corresponding projection, $\mathbf{T}_{\text {anomalies }}$, over three different analysis periods, the first one containing leakage $F S 1$, the second one without any leakage but with a visible drain and the third one with leakage $F S 2$. The two leakages are detected with a relatively significant amplitude with respect to the background.

The attention is next shifted to the temperature data acquired at the real dike presented in Figure 7. In addition to the normalization step in preprocessing, the higher order statistics criterion is also applied for identification of precipitation periods. The main analysis is carried out in temporal sliding windows of 14 days, chosen empirically. The first singular value, $\sigma_{1}$, accounts for $81 \%$ of the total signal and the corresponding SVD source does not contain any information pertinent to the leakages. It depicts two different temperature levels, corresponding to Zones 1 and 2 of Figure 6. The investigation of the site's topology revealed that these two zones correspond to different elevation levels with Zone 2 at a higher elevation as compared to Zone 1 . Moreover, a ground singularity is also identified in the zone between 1.6 and $1.7 \mathrm{~km}$. The source can thus be attributed to the ground response. The output of the detection scheme gives the leakage subspace, $\mathbf{Y}_{\text {leakages }}$, of Figure 11(a). A zoom in the vicinity of the artificial leakages, $L 1, L 2$, and $L 3$, shows an efficient detection and localization of the artificial leakages. The temporal evolution of these leakages can also be followed with this image. Among the three leakages, $L 1$ is detected as being the most energetic, followed by $L 2$. However, $L 3$ is detected with the least energy due to several reasons, low flow rate and its 


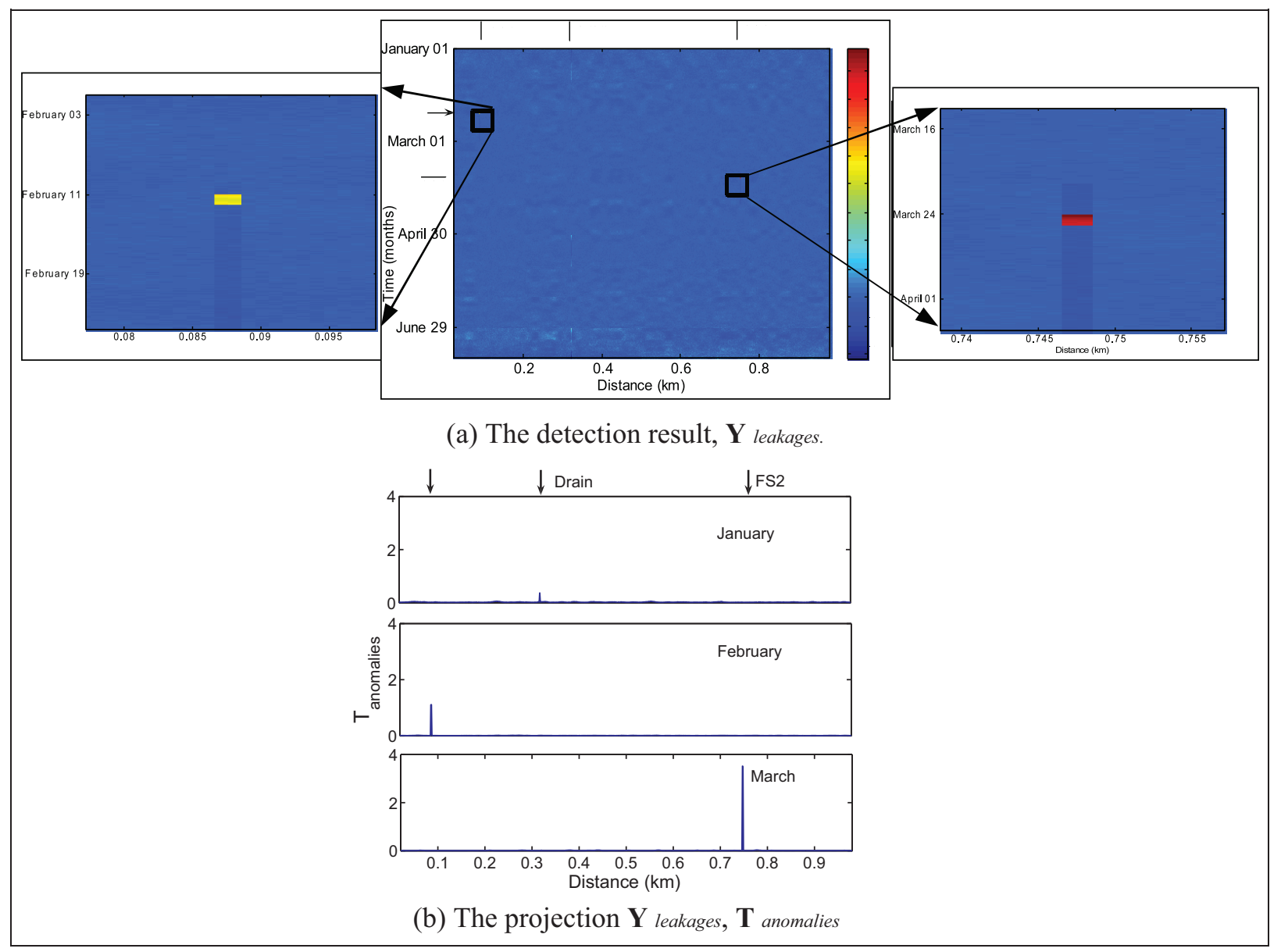

Figure 10. Source separation-based (medium-term approach) detection results for the simulated data with zoom in the vicinity of leakages: (a) detection in time-space with resolution of $2 \mathrm{~h}$ and $\mathrm{I} \mathrm{m}$ and $(\mathrm{b})$ projection on the distance axis.

initiation during the night when the difference of temperature between that of water and air is not significant. Figure 11(b) shows the projection $\mathbf{T}_{\text {anomalies }}$ during October 2005. This projection reveals real leakages just before and after the second drain, $D 2$. These leakages, not detected earlier, diffuse, spreading over several meters, before being captured by the optical fiber. The periodic analysis done for the data acquired in October 2007 for the same site confirms detection of real leakages as shown by the projection of Figure 11(c).

The influence of different parameters of this source separation-based scheme was studied in detail. ${ }^{32}$ It was found that the background noise of the detection result depends on the instrument noise. The choice of the size of temporal analysis window depends on the nature of the researched leakages, a period of 2-3 weeks was found optimal for the sites studied. The underlying basis of this method being ICA, generic parameters cannot be defined for this approach. The parameters have to be adapted for each site and their choice depends on the topography and the number and intensity of leakages. However, on the other hand, the flexibility provided by different parameters of the scheme enhances its adaptability to different situations. In future, the problem can be modeled using the Bayesian approach using some a priori information on the suspected leakages or some geological parameters of the inspected site.

\section{Application of alarm system approach}

This section concerns the application of proposed alarm system of Figure 9 to the raw temperature data. As a preprocessing step, the meteorological conditions are initially verified to avoid the precipitation periods for the temperature data of the real site. A probability of false alarm of $10^{-5}$ was chosen. In principle, it needs to be adapted individually for each test site in consultation with the experts. First, the simulated data set containing the two leakages $F S 1$ and $F S 2$ along with a drain is analyzed. The current approach being based on daily temperature variation analysis, the leakages were simulated over 3 days in order to study their temporal evolution. 


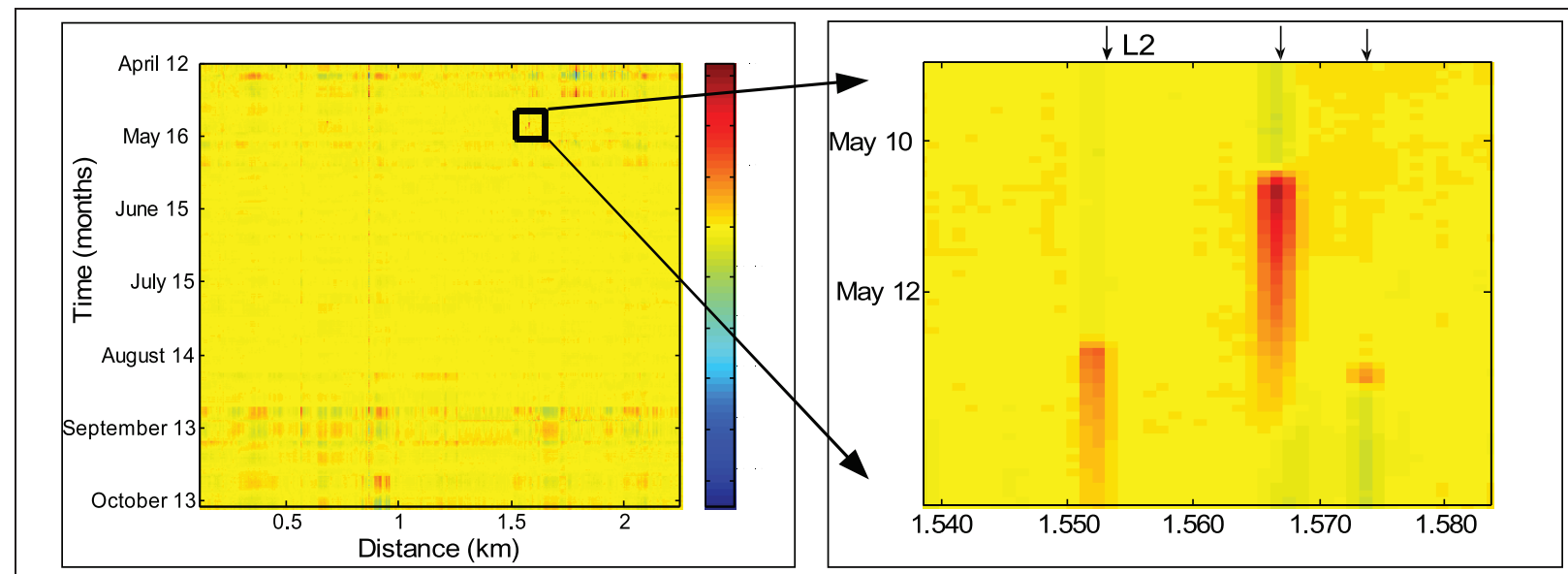

(a) The detection result, $\mathbf{Y}$ leakages.

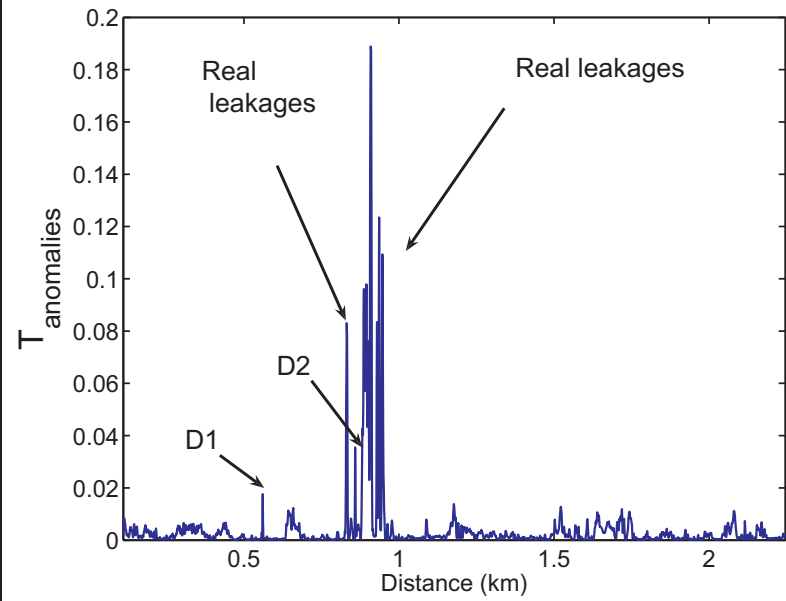

(b) The projection $\mathbf{T}$ anomalies in October 2005

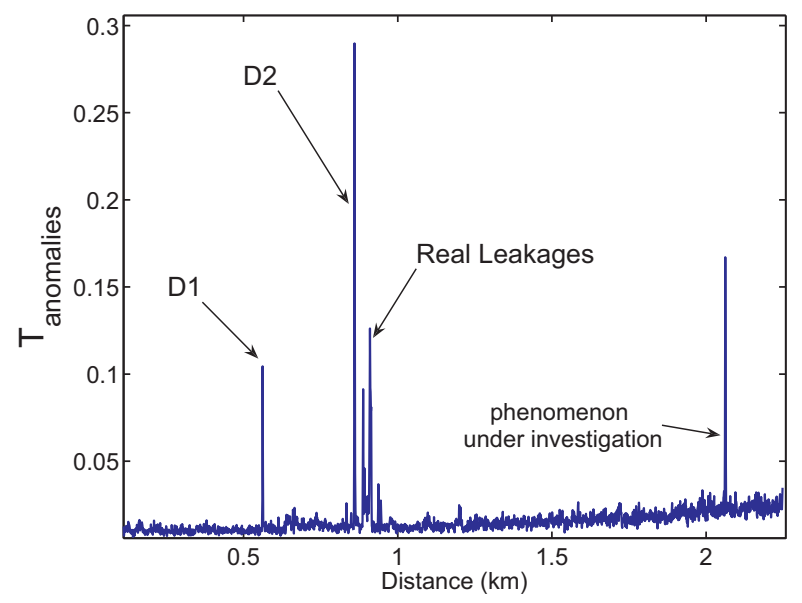

(c) The projection $\mathbf{T}$ anomalies in October 2007

Figure II. Source separation-based detection results for the real experimental data site with zoom in the vicinity of leakages and hot point: (a) detection in time-space with resolution of $2 \mathrm{~h}$ and $\mathrm{I} \mathrm{m}$, projection on distance axis (b) October 2005, and (c) October 2007.

It should be recalled here that unlike the source separation method, the present method takes the raw temperature over a 24 -h period as its input. The intermediate analysis steps not fitting into the scope of this article, only the final detection results are presented in Figure 12. The detection parameter is the thresholded dissimilarity measure, $d_{t h}^{k}(x)$, represented in Figure 12(a) for all the analysis days and distances. This image, constructed by concatenation of the daily analysis results, allows singularity detection with a spatial resolution of $1 \mathrm{~m}$ and a temporal resolution of $24 \mathrm{~h}$. The detection parameter permits localization of singularities constituted here by the two leakages and the drain (Figure 12(b)). The top window presents the results for 11 February, the day when leakage $F S 1$ was active; the middle window presents the case when none of the leakages was open, whereas the bottom window presents the results for 23 March, when leakage FS2 was open. It can be observed that the two leakages and the drain constituting the singularities are observed with their exact localization.

The results of daily analysis methodology on the real temperature data are shown in Figure 13. Figure 13(a) shows the daily detection results over the entire analysis period. The thresholded detection parameter allows identification of the artificial leakages $(L 1, L 2$, and $L 3$ ) as well as the hot point (HP)in addition to the drains (D1 and D2). The detection parameter for 3 days in 2005, (top) 10 May: leakage L1; (middle) 13 May: leakages $L 3, L 2$, and $L 1$; and (bottom) 20 July: no leakages, are illustrated in Figure 13(b). The leakages, being of impulsive nature, are very well localized by the detection parameter, whereas their relative amplitudes give information regarding strength of the underlying 


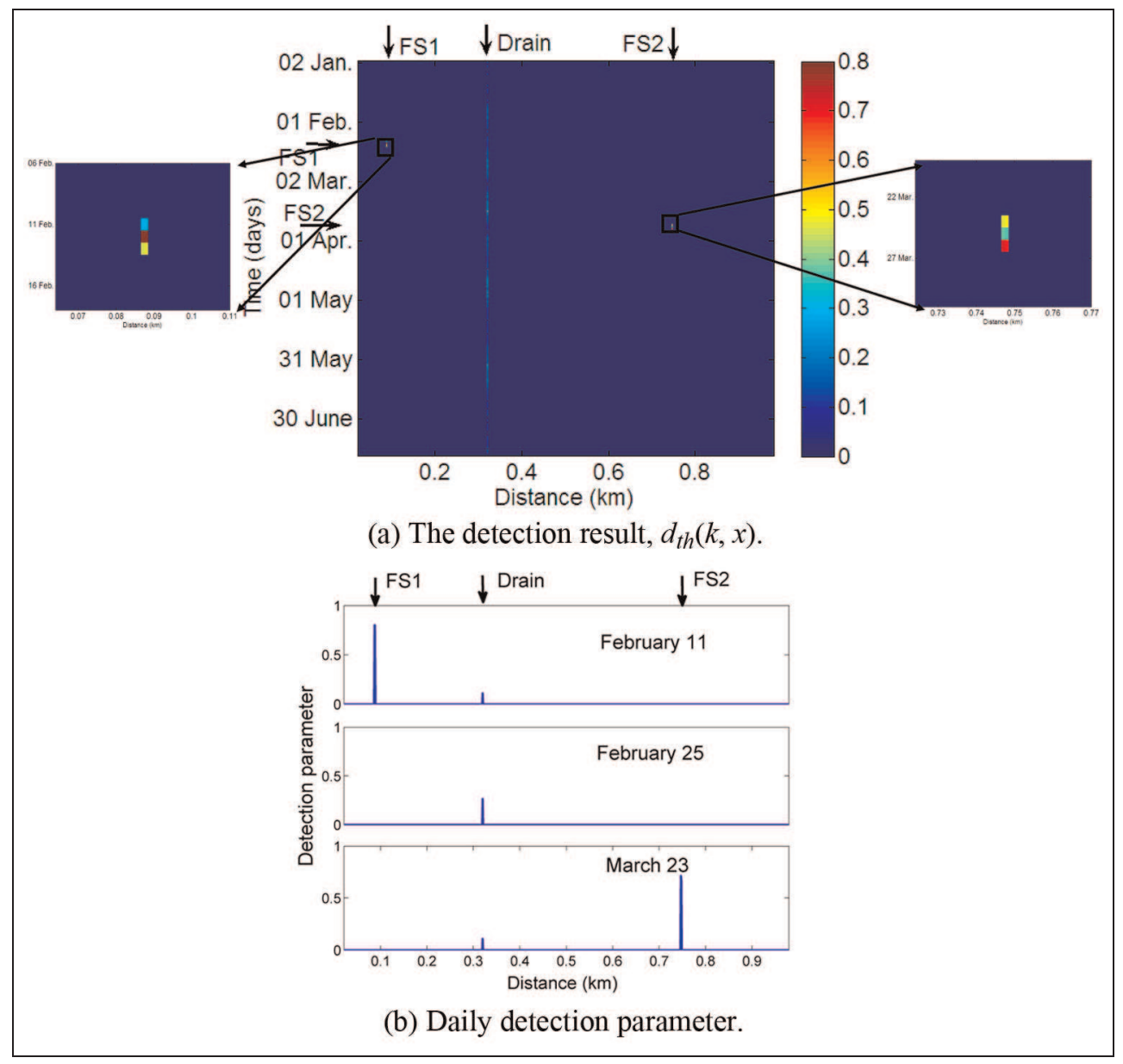

Figure 12. Alarm system-based detection results for the simulated data with zoom in the vicinity of leakages: (a) detection in timespace with resolution of $24 \mathrm{~h}$ and I $\mathrm{m}$ and (b) detection parameter for day with FSI (top), without leakages (middle), and with FS2 (bottom).

leakages. The singularities detected during this period are the two drains, $D 1$ and $D 2$, the three artificial leakages, $L 1, L 2$, and $L 3$, the hot point, $H P$, and the ground singularity around $1.7 \mathrm{~km}$.

In order to highlight the detection of real leakages and repeatability by the daily analysis approach, Figure 13(c) shows the detection parameter obtained on 9 October 2005 (top) and on 21 October 2007. In 2005, the major singularities detected are the drains and the real leakages around the drain $D 2$. The real leakages detected are spread over several meters, and a profound on-site physical investigation is underway for their characterization. The analysis during the same period 2 years later in 2007 confirms the presence of an anomaly in the same zone.

The proposed method successfully detects all the singularities including the leakages on a daily basis. The strength of the method lies in the fact that it estimates a reference from the acquired data themselves without requiring external variables. Due to this implicit reference estimation, the method will not be suitable when more than $50 \%$ of the inspected dike suffers from leakages. In this case, the reference will not solely be a representative of the non-singular zones and will incorporate major information from leakages. For addressing such a situation, external variables like air or water temperature could be used to approximate the reference, which will be taken up in some future work.

In brief, the proposed monitoring and early warning system approaches form a very powerful tool for water leakage detection using optical fiber thermometry. The synthetic dike generation model allows simulation of different leakage configurations in terms of leakage flow rate, duration, length, and so on. Moreover, the feasibility of optical fiber positioning inside the dike can also be studied. Exhaustive tests were performed in this regard, but they do not fit into the scope of this article and accordingly, some example cases were presented in this article. 


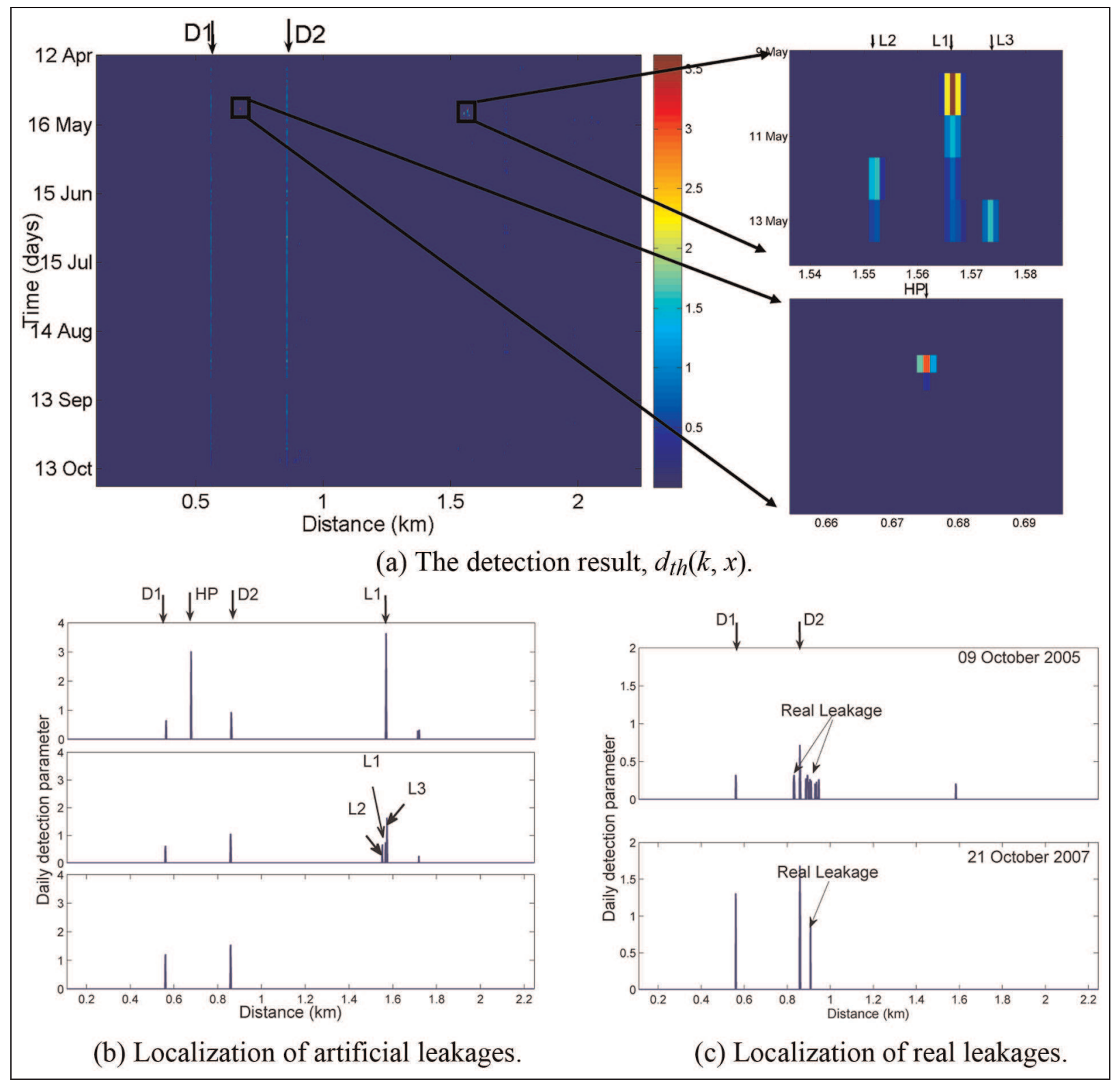

Figure 13. Daily analysis-based detection results for the real experimental data site: (a) detection in time-space, (b) artificial leakage localization, and (c) real leakage localization on 9 October 2005 and 21 October 2007.

\section{Conclusion}

Internal erosion, one of the major pathology of embankment dams, results in a significant lateral flow, a leakage, as a preferential path for seepage is developed. Leakage can also occur without developing significant internal erosion; however, the detection of leakage warrants further investigation. The leakage changes the local thermal field of the structure, thus making temperature an important indicator. The dikes, extending over several kilometers, necessitate development of efficient surveillance systems for improving the safety of the structure. On one hand, these systems should be capable of providing long-term monitoring, while on the other hand, they should be adaptable as early warning systems. The latter notion is important because case studies have revealed that the time between initial observation of an anomaly through visual inspections and eventual dike rupture can be very short. In this regard, using the fiber as a continuous temperature sensor may be a very efficient solution for temperature measurements with spatial and temperature resolutions of $1 \mathrm{~m}$ and $0.05^{\circ} \mathrm{C}$, respectively. Moreover, optical fibers are capable of probing long distances up to several tens of kilometers. However, the 
raw temperature data are difficult to interpret in terms of leakage detection. This article presents a case study based on signal-processing detection algorithms, previously proposed by the authors. In particular, two systems were presented: a medium-term approach useful for monitoring and an early warning system-based alarm approach for daily temperature analysis. The resultant techniques were validated for both simulated and real site data where they allowed detection of artificial as well as real leakages. In addition, the detection parameter could allow following the temporal evolution of the detected leakages. Although only two data sets were chosen for presentation in this article, the proposed methods were validated on other test sites as well, most recently for a European project dedicated to the test of recent sensor technologies for surveillance purposes. ${ }^{33}$ The proposed methods allow detection of leakages prior to their identification through visual inspections. The optical fiber thermometry is a powerful tool to complement the existing method based on visual inspection.

\section{Declaration of conflicting interests}

The authors declare that there is no conflict of interest.

\section{Funding}

This research received no specific grant from any funding agency in the public, commercial, or not-for-profit sectors.

\section{References}

1. Fell R and Fry JJ. Internal erosion of dams and their foundations. London: Taylor \& Francis, 2007.

2. Fry JJ. Détection de fuite sur les digues par acquisition de profils de température le long d'une fibre optique. In: Sécurité des digues fluviales et de navigation, actes de colloque du CFGB, Orléans, 25-26 November 2004 (in French).

3. Boleve A, Revil A, Janod F, et al. A new formulation to compute self-potential signals associated with ground water flow. Hydrol Earth Syst Sci Discuss 2007; 4: 1429-1463.

4. Sjödahl P, Dahlin T and Johansson S. Embankment dam seepage evaluation from resistivity monitoring data. Near Surf Geophys 2009; 7(5-6): 463-474.

5. Vogt T, Schneider P, Hahn-Woernle L, et al. Estimation of seepage rates in a losing stream by means of fiber-optic high-resolution vertical temperature profiling. J Hydrol 2010; 380(1-2): 154-164.

6. Fargier Y, Palma-Lopes S, François D, et al. Optimization of electrode layouts for 3D-resistivity imaging: application to water infiltrations in an experimental dike. In: Proceedings of the 16th European meeting of environmental and engineering geophysics, Zurich, 6-8 September 2010.

7. Boleve A, Janod F, Revil A, et al. Localization and quantification of leakages in dams using time-lapse selfpotential measurements associated with salt tracer injection. J Hydrol 2011; 403(3): 242-252.
8. Ikard S, Revil A, Jardani A, et al. Saline pulse test monitoring with the self-potential method to nonintrusively determine the velocity of the pore water in leaking areas of earth dams and embankments. Water Resour Res 2012; 48(4): 1-17.

9. Bennett V, Abdoun T, Zeghal M, et al. Real-time monitoring system and advanced characterization technique for civil infrastructure health monitoring. Adv Civ Eng 2011; 2011: 870383 (12 pp.).

10. Bolève A, Revil A, Janod F, et al. Preferential fluid flow pathways in embankment dams imaged by self-potential tomography. Near Surf Geophys 2009; 7(5-6): 447-462.

11. Tchoumkam LN, Chouteau M, Giroux B, et al. A case study of the self-potential method to characterize seepage and earth dam materials. In: Buyukozturk O, Tasdemir MA, Gunes O, et al. (eds) Nondestructive testing of materials and structures. Dordrecht: Springer, 2013, pp. 943-948.

12. Armbruster H, Brauns J, Mazur W, et al. Effect of leaks in dams and trials to detect leakages by geophysical means. In: Merkler G, Militzer H, Hötzl H, et al. (eds) Detection of subsurface flow phenomena (Lecture Notes in Earth Sciences). Berlin, Heidelberg: Springer-Verlag, 1989, pp. 3-18.

13. Johansson S and Sjödahl P. Downstream seepage detection using temperature measurements and visual inspection-monitoring experiences from Rösvatn field test dam and large embankment dams in Sweden. In: Proceedings of the international seminar on stability and breaching of embankment dams, Oslo, 21-22 October 2004.

14. Hartog AH. Distributed fiber-optic temperature sensors: principles and applications. In: Grattan KT and Meggitt BT (eds) Optical fiber sensor technology. Dordrecht: Kluwer Academic Publishers, 2000, pp. 241-301.

15. Grosswig S, Graupner A and Hurtig E. Distributed fiber optical temperature sensing technique - a variable tool for monitoring tasks. In: Proceedings of the 8th international symposium on temperature and thermal measurements in industry and science, Berlin, 19-21 June 2001, pp. 9-17. Berlin: VDE-Verlag.

16. Tyler SW, Selker JS, Hausner MB, et al. Environmental temperature sensing using Raman spectra DTS fiberoptic methods. Water Resour Res 2009; 45(4): 362-373.

17. Vedrenne C, Fabre J-P, Courivaud JR, et al. Détection et quantification des fuites par thermométrie distribuée le long d'une fibre optique (leakage detection and quantification by distributed temperature measurements along fiber optic. In: Proceedings of the 23rd international conference on large dams, CIGB-ICOLD, Brasilia, Brazil, 2529 May 2009.

18. Khan AA, Vrabie V, Mars J, et al. A source separation technique for processing of thermometric data from fiberoptic DTS measurements for water leakage identification in dikes. IEEE Sens J 2008; 8: 1118-1129.

19. Khan AA, Vrabie V, Mars J, et al. Automatic monitoring system for singularities detection in dikes by DTS data measurement. IEEE T Instrum Meas 2010; 59(8): 2167-2175. 
20. Fry JJ. Internal erosion and surveillance. In: ICOLD 19th congress, Florence, 26-30 May 1997.

21. Dornstädter J. Detection of internal erosion in embankment dams. In: ICOLD 19th congress, Florence, 26-30 May 1997.

22. Johansson S. Localization and quantification of water leakage in ageing embankment dams by regular temperature measurements. In: Proceedings of the ICOLD, 17th congress, Vienna, 17-21 May 1991.

23. Nikles M. Fibre optic distributed scattering sensing system: perspectives and challenges for high performance applications. In: Proceedings of the third European workshop on optical fibre sensors, Napoli, 4 July 2007.

24. Guidoux C. Développement et validation d'un système de détection et de localisation par fibre optiques de zones de fuites dans les digues en terre. PhD Thesis, University Joseph Fourier, Saint-Martin-d'Hères, 2008 (in French).

25. Diersch HJG and Kolditz O. WASY software FEFLOW: finite element subsurface flow and transportation simulation system (White papers, vol. II). Berlin: WASY Institute for Water Resources Planning and systems research, 2005.
26. Beck Y, Khan AA, Cunat P, et al. Thermal monitoring of embankment dams by fiber optics. In: Proceedings of the 8th ICOLD European club symposium on dam safety, Innsbruck, 22-23 September 2010.

27. Khan AA, Vrabie V, Mars JI, et al. A least square approach for bidimensional source separation using higher order statistics criteria. In: Proceedings of the EUSIPCO, Lausanne, 25-29 August 2008.

28. Klema VC and Laub AJ. The singular value decomposition: its computation and some applications. IEEE T Automat Contr 1980; 25(2): 164-176.

29. Hyvärinen A, Karhunen J and Oja E. Independent component analysis. New York: Wiley, 2001.

30. Comon P and Jutten C. Handbook of blind source separation. Oxford: Elsevier, 2010.

31. Cardoso JF and Souloumiac A. Blind beamforming for non-Gaussian signals. IEE Proc: F 1993; 140(6): 362-370.

32. Khan AA. Séparation de sources thermométriques. $\mathrm{PhD}$ Thesis, INP Grenoble, Grenoble, 2009 (in French).

33. Artieres $\mathrm{O}$ and Pinettes P. Early detection of dams and dikes anomalies with a fibre-optics based monitoring solution. In: Joint UrbanFlood \& SSG4Env workshop, Amsterdam, 11-12 November 2010. 